\title{
SUICIDE ATTEMPT AND METABOLIC SYNDROME, A CASUAL RELATIONSHIP?
}

Author: Vasquez F., Aliaga S., Nicolas Y., Falconi S. National Institute of Mental Health Lima Peru.

DISCLOSURE: No conflict of interest.

OBJECTIVE: To study association of suicide attempt and Metabolic Syndrome (MS) in patients assisted at Emergency Room.

BACKGROUND AND AIMS: Metabolic Syndrome is one of most important problems of public health with cardiovascular risk factors, hypertension, obesity, dyslipidemia, glucose intolerance, and recent studies look its association with Affective Disorders, like Depression and the worst consequence like suicidal events.

METHODS: A descriptive, longitudinal study of patients seen at Emergency Room who attempted suicide also with criteria for MS, in a two-year period 2016-2017, with participation of Medical Team and Prevention Suicide Program. Clinical Histories with ICD 10 Criteria, Hamilton Scale for Depression, Pierce Scale for Suicide were applied for assessment.

RESULTS: Of 1320 assessed patients, they were found MS in 130 patients (9.8\%) who made suicide attempt; Female were $112(86.1 \%)$ and Male $18(13.9 \%)$. Age Interval was18 to 68 years old. (y.o).

Age distribution: $18-25$ y.o: $19.2 \%$; $26-33$ y.o: $23.8 \%$; $34-41$ у.о: $22.3 \%$, $42-49$ y.0: $24.6 \%$, 50-57 y.0: $3.9 \% 58$ y.o or more: $6.1 \%$. Clinical diagnoses were: Major Depressive Disorder: $44.6 \%$, Bipolar Disorder: 32.3\%, Schizophrenic Disorder: 15.4\%, Anxiety Disorder: 4.6\%, Obsessive Compulsive Disorder: 3.1\%. Co morbid diagnoses: Borderline Personality Disorder: 27.7\%, Alcohol \& Psychoactive Substances Disorder: 14.3\%, Pathological Gambling: 3.1\%. Respect to MS and severity: Moderate: $66.2 \%$, Severe: $30 \%$, Very Severe: $3.1 \%$ Extreme severity: $0.8 \%$

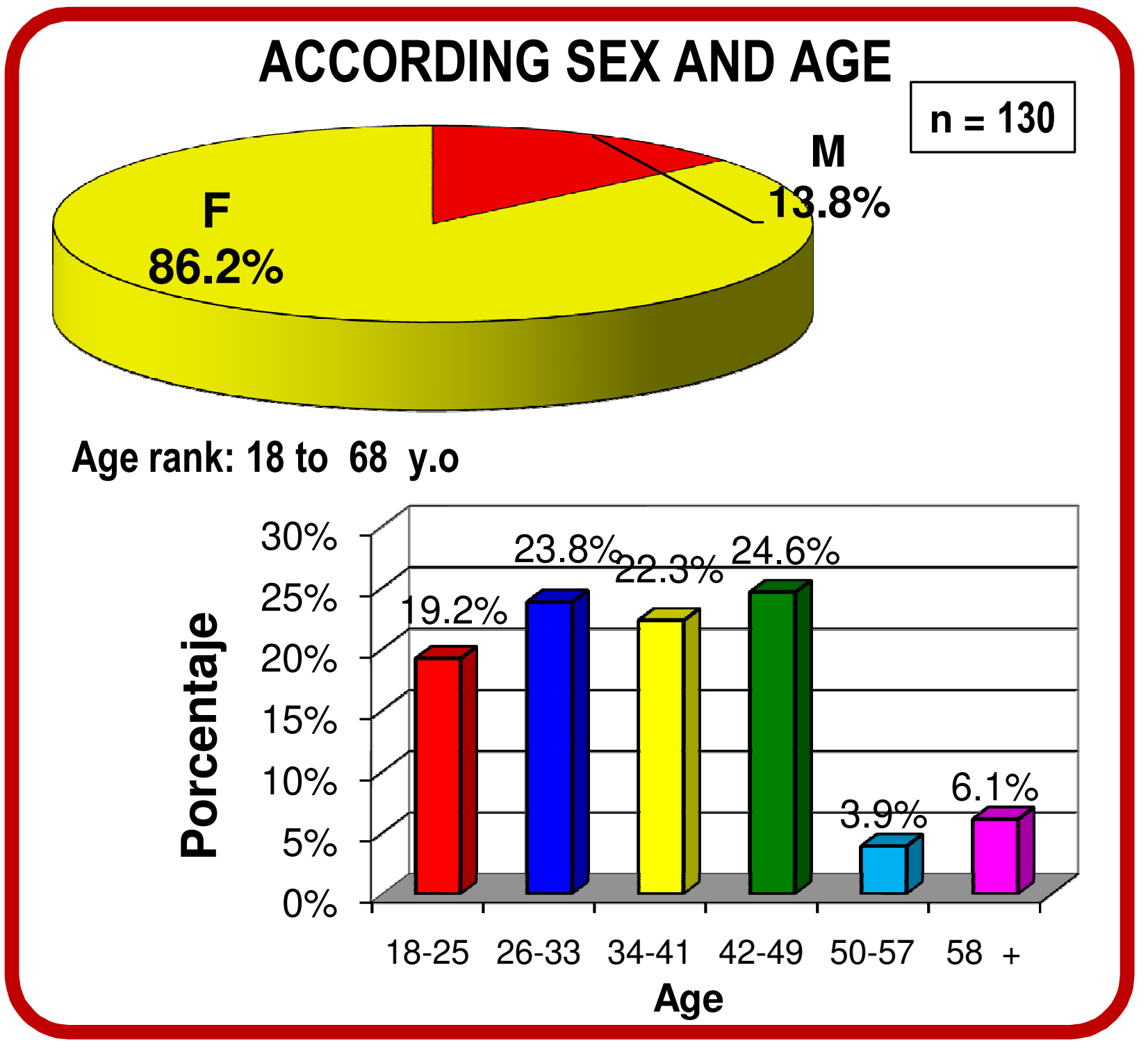

CONCLUSIONS: This trial shows almost $10 \%$ of suicidal attempters affected by MS, and Affective Disorders were present in more than a half of them. It is important similar degree of compromise among adult and Young people, and is very worry the predominance of very severe degree of MS in more than thirty of studied population. It seems difficult to show an etiological association for both conditions, but it looks that MScould be another risk factor for suicidal attempt.
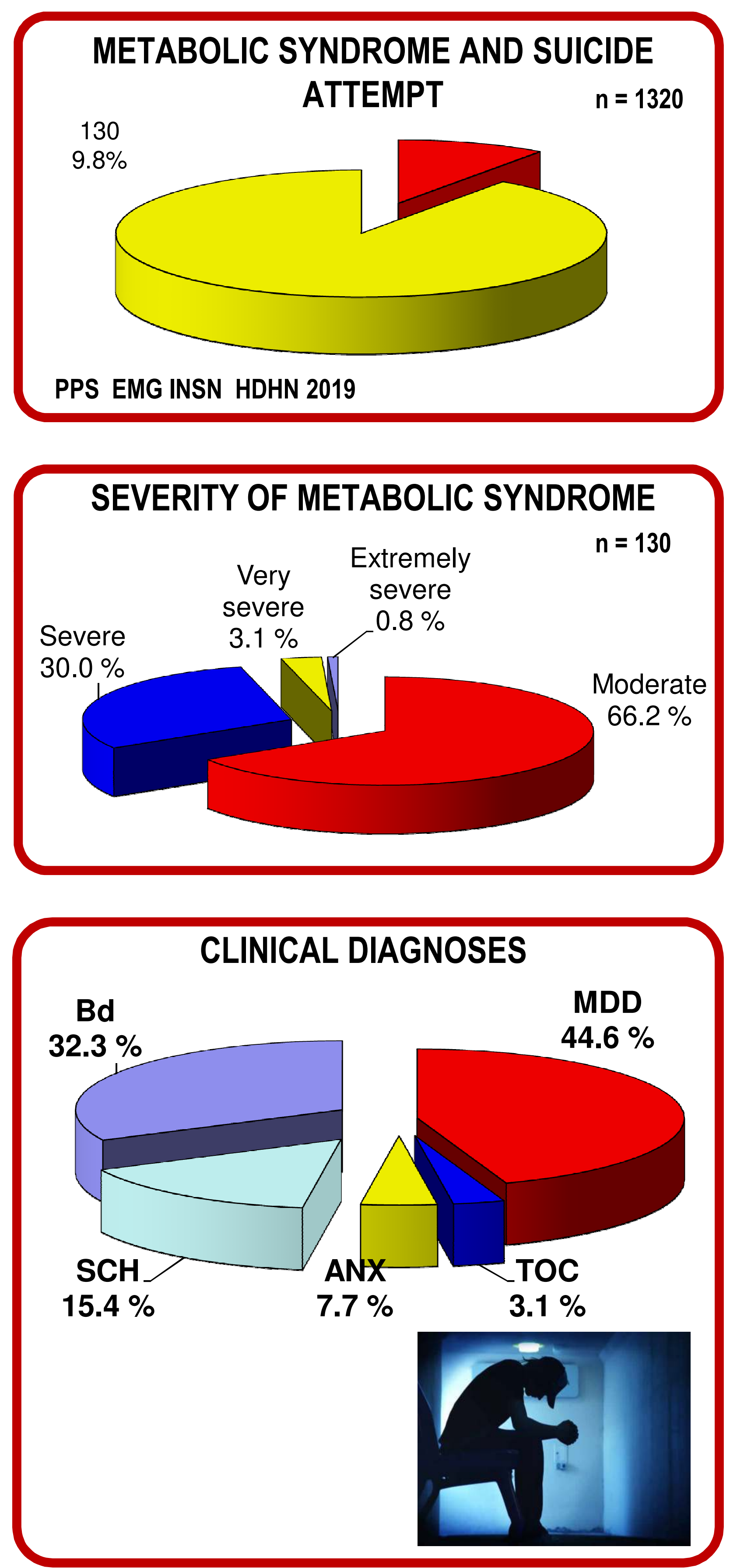

Eckel RH, Grundy SM, Wimmwt PZ 2005, The metabolic syndrome. Lancet, 2005; 365:1415.28 Medline.

Mayuri G. Esther, 2018 Depresión asociada al Sindrome Metabólico en pacientes del

Hospital Vitarte, Lima Perú, 2018 , 102 Tesis mayuri guisgueta.pdf, Lima 